\title{
Sistem Temu Kembali Informasi Dinas Pemuda Olahraga dan Pariwisata Kabupaten Purbalingga dengan Metode Vector Space Model
}

\author{
Muhammad Syafiq H ${ }^{\# 1}$, Sisilia Thya Safitri ${ }^{\# 2}$, Rifki Adhitama ${ }^{\# 3}$ \\ \# Institut Teknologi Telkom Purwokerto \\ Jl. DI Panjaitan No 128, Purwokerto, Jawa Tengah Indonesia \\ ${ }^{1} 15102108 @$ ittelkom-pwt.ac.id \\ ${ }^{2}$ sisil@ittelkom-pwt.ac.id \\ ${ }^{3}$ rifki@ittelkom-pwt.ac.id
}

Accepted on 18-05-2020

\begin{abstract}
Abstrak
Pariwisata di Indonesia kini sudah semakin meningkat baik pariwisata alami, maupun buatan. Kabupaten Purbalingga dapat dikatakan sebagai kabupaten yang sedang tumbuh terutama dalam bidang pariwisatanya dan mulai dijadikan sebagai perbandingan dengan pariwisata di kota lain di Jawa Tengah. Sistem Temu Kembali Informasi merupakan optimalisasi dalam pencarian website agar user mendapatkan informasi sesuai dengan yang diharapkan. Pariwisata di Kabupaten Purbalingga masih mengalami kendala yaitu aspek dalam memberikan informasi secara detail objek wisata. Penggunaan sistem temu kembali diharapkan dapat digunakan sebagai optimalisasi pencarian untuk meningkatkan relevansi antara query dengan dokumen pariwisata Kabupaten Purbalingga. Tools yang akan digunakan untuk membuat sistem temu kembali informasi ini yaitu dengan framework codeigniter kemudian bahasa pemrograman php untuk website dengan penyimpanan data menggunakan database Mysql. Dalam proses pembangunan sistem temu kembali informasi diperlukan sebuah algoritma yaitu vector space model sebagai perhitungan relevansi antara query dengan dokumen. Penerapan sistem temu kembali informasi pariwisata Kabupaten Purbalingga, diharapkan dapat membantu kondisi pariwisata di Kabupaten Purbalingga menjadi meningkat khususnya dalam informasi pariwisata. Hasil penelitian ini adalah website pencarian yang akan memberikan informasi objek wisata sesuai dengan query yang diinputkan oleh user kemudian menampilkan dokumen secara relevan dengan query.
\end{abstract}

Kata Kunci: Temu Kembali Informasi,Pariwisata Kabupaten Purbalingga, Vector Space Model

\section{PENDAhULUAN}

M ulai banyaknya objek wisata yang ada di Purbalingga membuat tantangan baru bagi Dinas Pariwisata

Kabupaten Purbalingga untuk dapat memberikan informasi secara rinci dan detail kepada calon wisatawan. Selaku manajemen pariwisata di Kabupaten Purbalingga perlu adanya tindakan untuk dapat memberikan informasi kepada calon wisatawan terkait pariwisata Kabupaten Purbalingga. Dinas Pariwisata Kabupaten Purbalingga merupakan tangan dari wisata-wisata khususnya wisata yang baru muncul untuk dapat memberikan informasi. Fitur pencarian yang tersedia pada website Dinas Pariwisata Purbalingga saat ini 
belum optimal dikarenakan informasi yang disediakan hanya sebatas informasi prestasi dari suatu desa wisata maupun informasi kedatangan tamu yang berwisata di Kabupaten Purbalingga. Publikasi pariwisata di Kabupaten Purbalingga dianggap belum optimal karena belum ada website informasi yang lebih rinci terkait pariwisata yang ada di Kabupaten Purbalingga.

Pariwisata yang ada di Kabupaten Purbalingga saat ini sedang dalam proses pembangunan dan pencarian wisata-wisata alam. Gambar 1.1 dan gambar 1.2 merupakan grafik yang menunjukan data pengunjung/wisatawan lokal dan mancanegara yang berwisata di Kabupaten Purbalingga mulai dari tahun 2012 hingga tahun 2015. Data tersebut diambil dari sumber Badan Pusat Statistik Kabupaten Purbalingga dan Dinas Pariwisata Kabupaten Purbalingga[1].

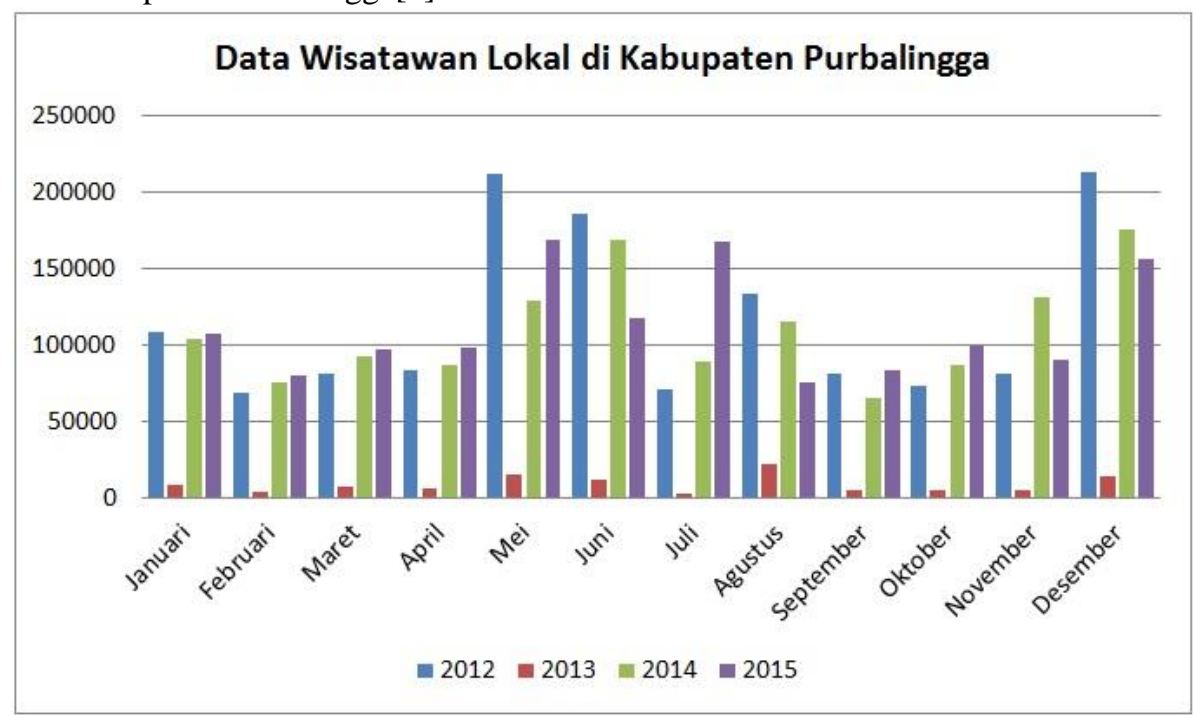

Gambar 1. Wisatawan Lokal Kabupaten Purbalingga Tahun 2012-2015

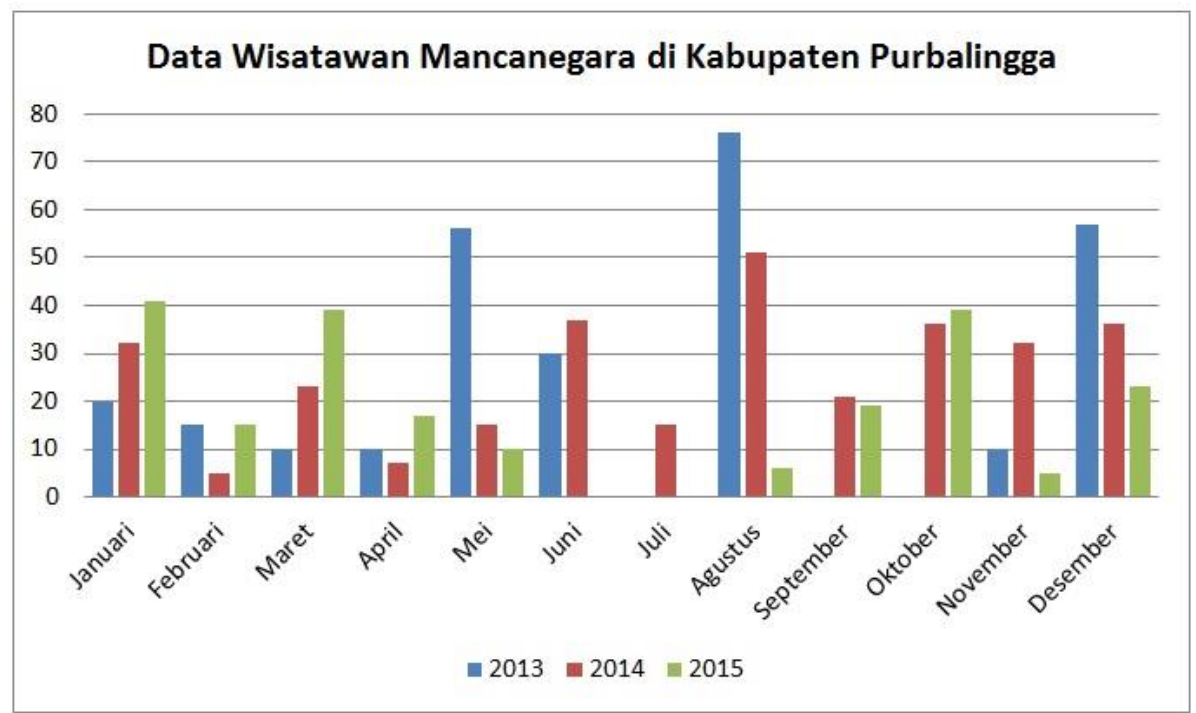

Gambar 2. Wisatawan Mancanegara Kabupaten Purbalingga Tahun 2012-2015

Metode vector space model merupakan sebuah metode yang memiliki fungsi sebagai perhitungan nilai dari kemiripan antara query yang dimasukkan oleh pengguna dengan dokumen yang tersedia pada website. Vector space model dapat digunakan sebagai algoritma pencarian yang efektif. Peran algoritma vector space model adalah untuk membantu mengoptimalkan agar wisatawan mendapat informasi pariwisata sesuai dengan query 
yang dimasukkan. Kemudahan dalam mencari informasi tersebut dapat memberikan kemudahan bagi seluruh wisatawan untuk mendapat informasi pariwisata kabupaten Purbalingga secara jelas dan detail.

Dalam penelitian ini, fokus masalah yang akan dilakukan sebagai penelitian adalah optimalisasi dari fungsi pencarian. Selain itu relevansi antara query dengan dokumen diperlukan agar dapat menghasilkan nilai tingkat kemiripan yang tinggi sehingga dapat menampilkan dokumen sesuai dengan query yang diinputkan oleh pengguna. Hal yang membedakan website ini dengan website pemerintah Kabupaten Purbalingga sebelumnya adalah penggunaan teknologi vector space model pada fungsi menu pencarian kata kunci sehingga pengguna dapat dengan mudah mencari sesuai apa yang diinginkan

Penelitian ini dilakukan untuk memberikan informasi secara jelas yang akan membantu para wisatawan yang ingin berwisata di Kota Purbalingga dengan mengoptimalkan dari menu fungsi pencarian. Penelitian ini diharapkan dapat membantu pemerintah Purbalingga dalam mewujudkan program pariwisata yang sudah di programkan oleh Dinas Pariwisata.

Berdasarkan latar belakang yang telah dituliskan, rumusan masalah yang diangkat dalam penelitian ini yaitu sebagai berikut yaitu kurangnya informasi mengenai desa wisata terkait seperti harga tiket dan fasilitas di Kabupaten Purbalingga. Kurangnya kata kunci relevan dan optimalisasi pada pencarian pariwisata Purbalingga yang detail.

Tujuan penelitian ini yang bersifat umum yaitu sebagai sistem informasi pariwisata dengan basis website yang akan memberikan kemudahan bagi wisatawan untuk memperoleh informasi seputar pariwisata Kabupaten Purbalingga. Selain itu, sistem ini nantinya akan memberikan informasi penjelasan lebih detail terkait pariwisata Kabupaten Purbalingga. Penelitian ini lebih khusus bertujuan untuk membantu optimalisasi pencarian pariwisata Kabupaten Purbalingga melalui website karena kabupaten Purbalingga yang dianggap berpotensi untuk menggunakan sistem ini.

\section{TINJAUAN PUSTAKA}

Dalam jurnal yang berjudul Penerapan Temu Kembali Informasi pada Kumpulan Dokumen Skripsi, Metode yang digunakan pada penelitian ini yaitu metode vector space model. Keluaran dari penelitiannya yaitu sistem temu kembali informasi dapat diterapkan pada penelitiannya. Hasil penelitiannya yaitu Dapat menemukan dokumen yang relevan terhadap kata kunci. Menampilkan waktu proses indexing bahwa 100 dokumen dapat terindex dengan kurun waktu 328.85 detik. Nilai precision dokumen yang relevan yaitu antara 0.346154 sampai dengan 1 membuktikan bahwa dokumen relevan[2].

Dalam jurnal yang berjudul Pencarian Materi Kuliah pada Aplikasi Blended Learning menggunakan Vector Space Model. Metode vector space model yang digunakan dalam penelitiannya. Dapat melakukan proses pencarian walaupun stopword yag digunakan menggunakan bahasa Inggris. Hasil dari penelitian yaitu dapat mencari materi kuliah yang menggunakan metode vector space model dengan tingkat kemiripan $<60 \%$ dari jumlah keyword dengan durasi proses pencarian rata-rata $2.5 \operatorname{detik}[3]$.

Dalam jurnal yang berjudul Analisis Perbandingan Metode Vector Space Model dan Weighted Tree Similarity dengan Cosine Similarity pada Kasus Pencarian Informasi Pedoman Pengobatan Dasar di Puskesmas dengan metode yang digunakan yaitu vector space model dengan weighted similarity. Hasil dari penelitiannya yaitu membandingkan bahwa metode tree similarity merupakan metode terbaik dengan bukti dari sistem pakar, serta memberikan nilai precission lebih presisi[4].

Dalam jurnal yang berjudul Information Retrieval Tugas Akhir dan Perhitungan Kemiripan Dokumen Mengacu pada Abstrak menggunakan Vector Space Model. Hasil dari penelitiannya yaitu mencari tingkat kemiripan yang ada pada dokumen tugas akhir dengan berpedoman Abstrak sebagai pedoman untuk di proses indexing[5].

Dalam jurnal yang berjudul Pencarian Pasal pada Kitab Undang-Undang Hukum Pidana (KUHP) Berdasarkan Kasus menggunakan Meode Cosine Similarity dan Latent Semantic Indexing (LSI). Metode yang digunakan yaitu dengan metode Cosine Similarity dan Latent Semantic Indexing (LSI). Hasil dari penelitian berupa pengembangan sistem dalam pencarian pasal KUHP dinilai sesuai karena hasil dari Mean Average Precision (MAP) mendekati nilai 1[6]. 
Dalam jurnal yang berjudul Efektivitas Penggunaan Stoplist Kata Umum dari Dokumen Hasil Klasifikasi Pretopology. Metode yang digunakan yaitu dengan vector space model dengan klasifikasi dokumen dengan pretopology. Hasil dari penelitian bahwa klasifikasi dari 75 dokumen dengan menerapkan metode pretopology menghasilkan nilai recall serta precision sebesar 90\% dan 76\%[7].

Keunggulan dari penelitian sebelumnya yaitu sistem temu kembali informasi dengan metode vector space model ini akan di implementasikan dengan cakupan lebih detail yaitu kota/ Kabupaten Purbalingga. Penelitian ini bekerja sama dengan Dinas Pariwisata kabupaten Purbalingga sebagai pengelolaannya. Metode vector space model yang akan di implementasikan pada website pariwisata memiliki potensi sebagai salah satu faktor pendukung promosi pariwisata Kabupaten Purbalingga.

Dasar teori yang digunakan dalam penelitian ini yaitu:

1) Sistem Informasi: Definisi dari sistem yaitu suatu jaringan kerja dari prosedur yang saling berhubungan, berkumpul untuk melakukan sebuah kegiatan untuk mencapai suatu target tertentu. Definisi dari informasi yaitu suatu hasil dari pengolahan data dalam bentuk yang lebih mudah untuk dipahamani oleh penerima. Definisi dari sistem informasi yaitu sistem yang menyediakan suatu informasi untuk mendukung dalam pengambilan keputusan serta pengendalian di dalam[8].

2) Information retrieval merupakan sistem yang memiliki fungsi mengembalikan kembali informasiinformasi yang relevan terhadap keperluan pengguna dari kumpulan informasi secara otomatis. Information retrieval bekerja terhadap suatu dokumen atau informasi yang tidak memiliki struktur dan terhadap kebutuhan pengguna yang juga tidak memiliki struktur[9].

3) Vector space model adalah model dari Information Retrieval yang mempresentasikan dokumen dan query sebagai vektor pada ruang multidimensi. Persamaan suatu dokumen dapat dihitung dengan panjang vektor dari dokumen dan query. Vector space model akan menghitung bobot dari setiap term yang terdapat pada semua dokumen serta query dari pengguna. Term merupakan kumpulan kata dari satu kalimat yang ada pada dokumen. Relevansi dari term dokumen dengan query yang dimasukkan oleh user dapat dinilai sebagai pengukuran kesamaan nilai vektor. Perhitungan pada vector space model memiliki tahapan mulai dari pembobotan nilai term frequency-Inverse Document Frequency (TF-IDF) dan nilai dari persamaan term dengan menggunakan cosine similarity[10].

4) Proses Indexing memiliki tahapan yang harus dilakukan saat proses indexing. Penjelasan dari setiap tahapan sebagai berikut.

a. Teks

Teks merupakan dokumen yang akan diproses index mulai dari judul dan isi dari dokumen tersebut.

Dokumen akan ditampilkan ketika query dan dokumen bernilai relevan.

b.Tokenizing

Proses tokenization merupakan proses membagi kalimat dari dokumen yang sudah tersedia kemudian dipecah setiap kata dari kalimat tersebut.

c.Filtering

Pada proses ini dokumen yang akan di index akan di saring dengan menghilangkan kata penghubung serta tanda baca yang ada pada dokumen. Pada proses ini diperlukan stoplist atau stopword yang berisi kata penghubung supaya dapat dijadikan sebagai acuan saat proses indexing.

d.Stemming

Proses stemming berfungsi guna mengurai kata menjadi kata dasar. Proses ini akan menghilangkan imbuhan imbuhan kata agar menjadi kata dasar. Diperlukan dictionary sebagai acuan kata dasar untuk sistem dapat melakukan proses indexing.

e.Indexing

Tahap indexing ini merupakan hasil dari proses indexing dengan dokumen yang sudah di index akan membentuk suatu pola yang dapat dikenali oleh sistem sebagai dokumen[11].

5) Proses pencarian teks memiliki tahapan sebagai berikut. a.Query

Tahapan yang pertama yaitu user akan memasukan sebuah query yang nantinya akan dikembalikan oleh sistem menjadi sebuah informasi. 
b.Stemming

Pada tahapan ini sama halnya dengan proses indexing, sistem akan menghilagkan kata yang memiliki imbuhan agar menjadi kata dasar.

c.Pembobotan Dokumen

Proses pembobotan merupakan proses dari perhitungan bobot term dari query pengguna dan juga perhitungan dari term dokumen yang tersedia. Rumus yang digunakan untuk menghitung bobot atau yang bisa disebut term frequency (tf) yaitu sebagai berikut:

$$
W(d, t)=T F(d, t)
$$

$\mathrm{TF}(\mathrm{d}, \mathrm{t})$ merupakan term frequency dari term $\mathrm{t}$ yang ada pada text $\mathrm{d}$. Setelah perhitungan term frequency dilakukan perhitungan term yang muncul pada seluruh koleksi dokumen. Perhitungan ini disebut sebagai Inverse Document Frequency (IDF). Rumus persamaan dalam perhitungan IDF dinyatakan sebagai berikut:

$$
I D F(t)=\log \left(\frac{N}{d f(t)}\right)
$$

$\mathrm{N}$ merupakan total dari jumlah dokumen yang ada pada koleksi kemudian df (t) adalah jumlah dokumen yang mengandung term $t$. Berikut adalah rumus umum dari penggabungan perhitungan TFIDF dengan cara mengalikan nilai TF dan IDF sebagai berikut[9]:

$$
T F-I D F(d, t)=T F(d, t) \cdot I D F(t)
$$

d.Similarity Calculation

Proses ini merupakan perhitungan kemiripan antara dokumen dengan query. Hasil dari nilai similarity akan menjadi pengurutan dengan nilai tertinggi akan menjadi dokumen yang mirip dengan query. Menggunakan rumus cosine similarity dan persamaan rumus sebagai berikut[12]:

$$
\operatorname{Sim}\left(Q, D_{i}\right)=\frac{\sum_{i} W_{q, j} W_{i, j}}{\sqrt{\sum_{j} W_{q, j}^{2}} \cdot \sqrt{\sum_{i} W_{i, j}^{2}}}
$$

e.Retrieval Document

Tahap akhir ini merupakan hasil dari dokumen yang relevan dengan query yang diinput oleh pengguna kemudian ditampilkan oleh pengguna.

6) MySQL Database

MySQL merupakan sebuah database RDBMS (Relational Database Management System)yang bersifat open source dibuat oleh Michael Widenius.MySQL mampu menangani manajemen database mulai dari menangani beberapa user dengan instruksi sekaligus dalam satu waktu.Dalam hal ini, user merupakan sebagai administrator dari database, programmer aplikasi, sampai end user. MySQL dapat mengirim dan menerima data secara multi user dan cepat[13].

7) Metode (SDLC) System Development Life Cycle Waterfall

SDLC merupakan suatu metode untuk pembuatan maupun sebagai pengembangan aplikasi yang terdapat tahapan-tahapan dalam merancang aplikasi. Pada penelitian kali ini, metode SDLC yang digunakan yaitu waterfall.SDLC Waterfall merupakan metode yang mengumpamakan air terjun sebagai cara kerjanya. SDLC Waterfall memiliki beberapa tahap yang dikerjakan secara berurutan satu per satu[14].

\section{METODE PENELITIAN}

Berdasarkan uraian dari latar belakang, penelitian ini dilakukan pada Dinas Pariwisata Kabupaten Purbalingga. Subjek yang diteliti pada penelitian ini yaitu objek wisata yang ada pada Kabupaten Purbalingga, baik objek wisata alami maupun buatan. Penelitian ini memiliki beberapa tahapan dalam 
pembuatan sistem temu kembali informasi dengan vector space model. Mengacu pada metode SDLC waterfall tahapan tersebut dapat dilihat dalam gambar 3.1.

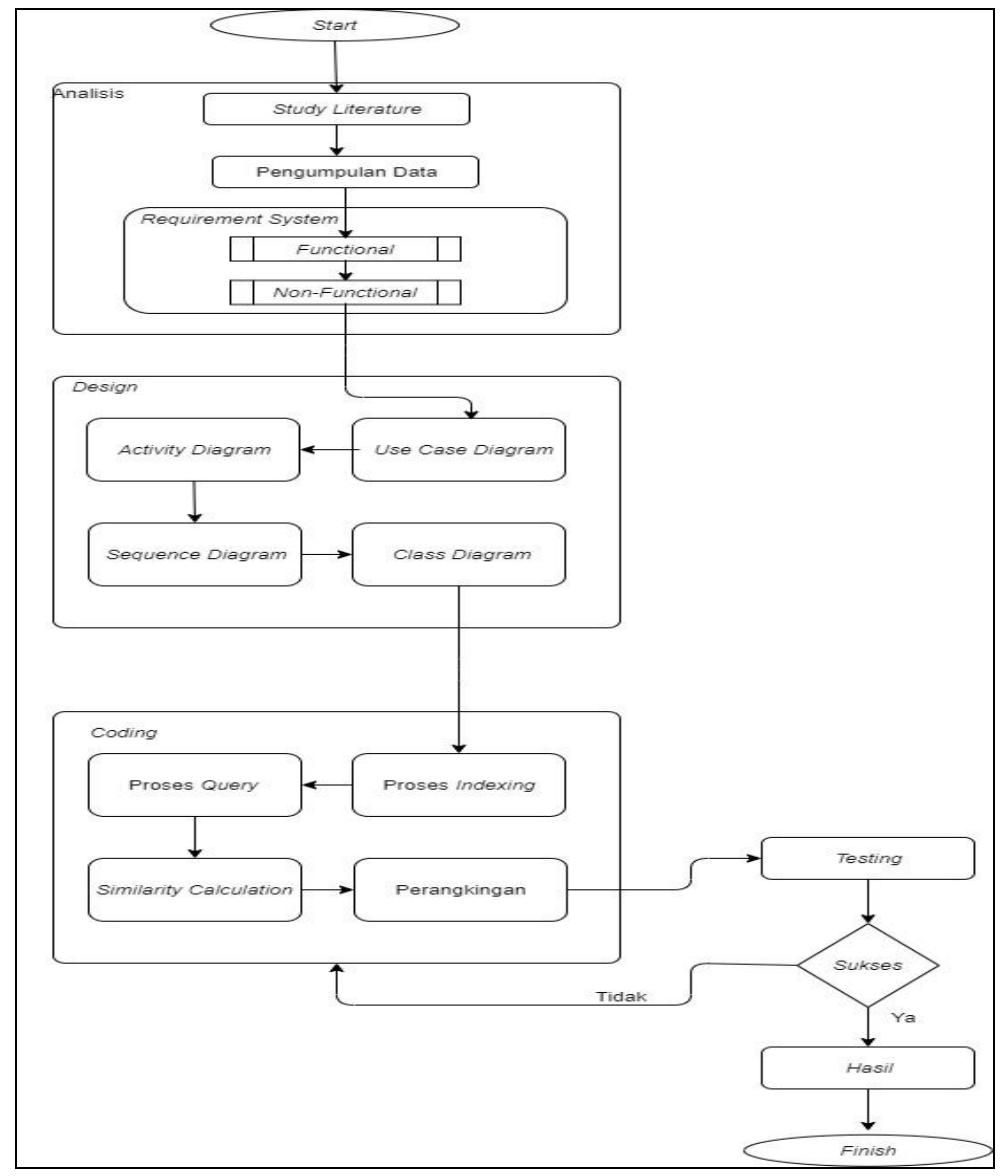

Gambar 3. Diagram Alir Penelitian

Dalam proses analisis, tahapan yang dilakukan yaitu dengan studi literature tentang algoritma vector space model dan materi temu kembali informasi serta ilmu lain yang dibutuhkan. Selanjutnya pengumpulan data data yang diperlukan.masih dalam proses analisis yaitu tahapan requirement atau membuat daftar kebutuhan yang dibutuhkan oleh sistem. Proses yang kedua yaitu proses design. Design ini yaitu dengan membuat diagram tentang alur dari kerja sistem. Terdapat 4 diagram yang diperlukan dalam membuat sistem ini yaitu use case, activity, sequence,dan class diagram. Proses selanjutnya yaitu pada proses inti yaitu coding. Coding dalam sistem yang dibuat dalam penelitian ini yaitu proses indexing, query, similarity calculation, dan perangkingan. Setelah proses coding selesai, akan diuji dengan metode blackbox testing dan pencarian nilai dari recall dan precision. Jika sistem berjalan sesuai dengan harapan. Maka penellitian dikatakan lancer, namun jika terdapat kendala, dapat di perbaiki pada proses coding.

\section{HASIL DAN PEMBAHASAN}

Berikut adalah sampel dokumen yang diproses menggunakan vector space model yang ada pada sistem ini.

1. Sampel dokumen sebagai perhitungan diambil 4 dokumen dengan judul sebagai berikut.

D1 = "Desa Wisata Serang"

D2 = "Goa Lawa Purbalingga"

D3 = "Kampung Kurcaci, Desa Serang"

D4 = "Taman Bunga Desa Siwarak Karangreja"

Query = "Wisata di Serang, Karangreja Purbalingga" 
2. Hitung Bobot

Tabel 4.1 Proses pencarian nilai IDF (Inverse Document Frequency)

\begin{tabular}{|c|c|c|c|c|c|c|c|c|}
\hline \multirow{2}{*}{ Terms } & \multirow{2}{*}{$\mathbf{Q}$} & \multicolumn{4}{|c|}{ TF (2.1) } & \multirow{2}{*}{ DF } & \multirow{2}{*}{ D/DF } & \multirow{2}{*}{$\begin{array}{l}\text { IDF } \\
(2.2)\end{array}$} \\
\hline & & D1 & D2 & D3 & D4 & & & \\
\hline Desa & 0 & 1 & 0 & 1 & 1 & 3 & $4 / 3$ & 0,124 \\
\hline Wisata & 1 & 1 & 0 & 0 & 0 & 1 & $4 / 1$ & 0,602 \\
\hline Serang & 1 & 1 & 0 & 1 & 0 & 2 & $4 / 2$ & 0,301 \\
\hline Kampung & 0 & 0 & 0 & 1 & 0 & 1 & $4 / 1$ & 0,602 \\
\hline Kurcaci & 0 & 0 & 0 & 1 & 0 & 1 & $4 / 1$ & 0,602 \\
\hline Purbalingga & 1 & 0 & 1 & 0 & 0 & 1 & $4 / 1$ & 0,602 \\
\hline Goa & 0 & 0 & 1 & 0 & 0 & 1 & $4 / 1$ & 0,602 \\
\hline Lawa & 0 & 0 & 1 & 0 & 0 & 1 & $4 / 1$ & 0,602 \\
\hline Taman & 0 & 0 & 0 & 0 & 1 & 1 & $4 / 1$ & 0,602 \\
\hline Bunga & 0 & 0 & 0 & 0 & 1 & 1 & $4 / 1$ & 0,602 \\
\hline Siwarak & 0 & 0 & 0 & 0 & 1 & 1 & $4 / 1$ & 0,602 \\
\hline Karangreja & 1 & 0 & 0 & 0 & 1 & 1 & $4 / 1$ & 0,602 \\
\hline
\end{tabular}

Tabel 4.2 Proses pencarian nilai bobot $(\mathrm{W})$

\begin{tabular}{|l|l|l|l|l|l|}
\hline \multirow{2}{*}{ Terms } & \multicolumn{5}{|c|}{ W= tf*idf (2.3) } \\
\cline { 2 - 6 } & Q & D1 & D2 & D3 & D4 \\
\hline Desa & 0 & 0,124 & 0 & 0,124 & 0,124 \\
\hline Wisata & 0,602 & 0,602 & 0 & 0 & 0 \\
\hline Serang & 0,301 & 0,301 & 0 & 0,301 & 0 \\
\hline Kampung & 0 & 0 & 0 & 0,602 & 0 \\
\hline Kurcaci & 0 & 0 & 0 & 0,602 & 0 \\
\hline Purbalingga & 0,602 & 0 & 0,602 & 0 & 0 \\
\hline Goa & 0 & 0 & 0,602 & 0 & 0 \\
\hline Lawa & 0 & 0 & 0,602 & 0 & 0 \\
\hline Taman & 0 & 0 & 0 & 0 & 0,602 \\
\hline \hline Bunga & 0 & 0 & 0 & 0 & 0,602 \\
\hline Siwarak & 0 & 0 & 0 & 0 & 0,602 \\
\hline Karangreja & 0,602 & 0 & 0 & 0 & 0,602 \\
\hline
\end{tabular}

Keterangan:
a. Term = Kata
b. Q = Query
c. $\mathrm{D}=$ Dokumen
d. $\mathrm{TF}=$ Nilai berdasar banyaknya term yang muncul pada dokumen
e. $\mathrm{DF}=$ Jumlah term yang dalam satu dokumen
f. IDF = Jumlah term pada seluruh dokumen
g. $\mathrm{W}=$ Bobot term pada dokumen 
3. Panjang Vektor

Proses pertama dalam perhitungan yaitu menghitung panjang vektor dari setiap dokumen beserta panjang vektor dari query. Perhitungan panjang vektor sebagai berikut.

$$
|\vec{a}|=\sqrt{a_{1}^{2}+a_{2}^{2}+\cdots+a_{n}^{2}}
$$

$|\vec{a}|=$ nilai mutlak panjang vektor

$a_{n}^{2}=$ nilai bobot dari terms yang muncul pada dokumen

$$
\begin{aligned}
& |\mathrm{D} 1|=\sqrt{(0,124)^{2}+(0,602)^{2}+(0,301)^{2}}=0,683 \\
& |\mathrm{D} 2|=\sqrt{(0,602)^{2}+(0,602)^{2}+(0,602)^{2}}=1,042 \\
& |\mathrm{D} 3|=\sqrt{(0,124)^{2}+(0,301)^{2}+(0,602)^{2}+(0,602)^{2}}=0,910 \\
& |\mathrm{D} 4|=\sqrt{(0,124)^{2}+(0,602)^{2}+(0,602)^{2}}+(0,602)^{2}=1,209 \\
& |\mathrm{Q}|=\sqrt{(0,602)^{2}+(0,301)^{2}+(0,602)^{2}+(0,602)^{2}}=1,084
\end{aligned}
$$

4. Hitung Dot Product

Tahap selanjutnya adalah menghitung dot product untuk memudahkan perhitungan dalam tahap selanjutnya yaitu nilai similarity.

$$
Q \cdot D_{i}=\sum_{i} W_{q, j} W_{i, j}
$$

$Q \cdot D_{i}=$ Perkalian nilai bobot dari query dengan dokumen i

$\sum_{i} W_{q, j} W_{i, j}=$ Jumlah dari perkalian antara query dengan dokumen yang muncul

$$
\begin{aligned}
& \text { Q.D1 }=0,602 * 0,602+0,301 * 0,301 \\
& =0,452 \\
& \text { Q.D2 }=0,602 * 0,602 \\
& =0,362 \\
& \text { Q.D3 }=0,301 * 0,301 \\
& =0,090 \\
& \text { Q.D4 }=0,602 * 0,602 \\
& =0,362
\end{aligned}
$$

5. Nilai Similarity

Perhitungan akhir yaitu proses mencari nilai dari kemiripan antara query dengan dokumen.

$$
\operatorname{Sim}\left(Q, D_{i}\right)=\frac{\sum_{i} W_{q, j} W_{i, j}}{\sqrt{\sum_{j} W_{q, j}^{2}} \cdot \sqrt{\sum_{i} W_{i, j}^{2}}}
$$

$\operatorname{Sim}\left(Q, D_{i}\right)=$ Perkalian nilai similarity antara query dengan dokumen

$\sum_{i} W_{q, j} W_{i, j}=$ Nilai Dot Product. 
$\sqrt{\sum_{j} W_{q, j}^{2}} \cdot \sqrt{\sum_{\mathrm{i}} W_{\mathrm{i}, j}^{2}} \quad=$ Perhitungan dari nilai panjang vektor query dengan panjang vektor dokumen $\mathrm{i}$

$\operatorname{Sim}\left(Q, D_{1}\right)=\frac{Q \cdot D_{1}}{|Q| x\left|D_{1}\right|}=\frac{0,452}{1,084 \times 0,683}=\frac{0,452}{0,740}=0,610$

$\operatorname{Sim}\left(Q, D_{2}\right)=\frac{Q \cdot D_{2}}{|Q| x\left|D_{2}\right|}=\frac{0,362}{1,084 \times 1,042}=\frac{0,362}{1,129}=0,320$

$\operatorname{Sim}\left(Q, D_{3}\right)=\frac{Q \cdot D_{3}}{|Q| x\left|D_{3}\right|}=\frac{0,090}{1,084 \times 0,910}=\frac{0,090}{0,986}=0,091$

$\operatorname{Sim}\left(Q, D_{4}\right)=\frac{Q \cdot D_{4}}{|Q| x\left|D_{4}\right|}=\frac{0,362}{1,084 \times 1,209}=\frac{0,362}{1,310}=0,276$

\section{Perangkingan}

Berikut adalah hasil akhir dari metode vector space model. Dengan kata kunci atau query yang dimasukkan oleh user yaitu "Wisata di Serang Karangreja Purbalingga". Outputnya diurutkan berdasarkan nilai similarity atau kemiripan yang tertinggi. Dari hasil perangkingan diatas dijelaskan bahwa dokumen 1 berada pada urutan pertama pada pencarian. Dibawahnya dokumen 2 kemudian dokumen 4 dan yang terakhir dokumen 3 yang ada pada pencarian.

Rangking 1 = Dokumen 1 (D1) "Desa Wisata Serang"

Rangking 2 = Dokumen 2 (D2) "Goa Lawa Purbalingga"

Rangking 3 = Dokumen 4 (D4) "Taman Bunga Desa Siwarak Karangreja"

Rangking 4 = Dokumen 3 (D3) "Kampung Kurcaci, Desa Serang"

\section{KESIMPULAN}

Berdasarkan hasil penelitian dan pembahasan pada bab sebelumnya, kesimpulan yang diperoleh yaitu sebagai berikut. Hasil dari pengujian sistem menggunakan blackbox testing dengan beberapa kriteria yang sudah dijelaskan pada bab sebelumnya bahwa seluruh kriteria pengujian yaitu sesuai harapan dengan tujuan dari penelitian. Hasil dari pencarian yang ditampilkan bernilai relevan dengan query yang dimasukkan oleh pengguna. Kecepatan dalam proses menampilkan dokumen dari query yang dimasukkan pengguna mendapatkan kecepatan sebesar 1,45 detik. Dengan demikian sistem ini telah sesuai dengan harapan yaitu saat menampilkan dokumen kurang dari 10 detik. Kesimpulan selanjutnya yaitu tingkat relevansi dari sistem temu kembali informasi yang di hitung berdasarkan nilai precision dan recall menampilkan yaitu $65 \%$ dan $100 \%$. Dapat di simpulkan bahwa sistem dianggap relevan dengan nilai diatas $50 \%$ 


\section{DAFTAR PUSTAKA}

[1] B. P. S. K. Purbalingga, “Jumlah Wisatawan Lokal dan Mancanegara Kabupaten Purbalingga,”2016.[Online].Available: https://purbalinggakab.bps.go.id/statictable/2016/10/21/83/jumlah-wisatawan-dan-pendapatan-dari-obyek-wisata-menurut-bulan-dikabupaten-purbalingga-2015.html.

[2] K. D. Putung, A. Lumenta, and A. Jacobus, "Penerapan Sistem Temu Kembali Informasi pada Kumpulan Dokumen Skripsi," Tek. Inform., vol. 8, no. 1, pp. 18-23, 2016.

[3] P. Angga, L. W. Astuti, and M. Ramadhan, "Pencarian Materi Kuliah Pada Aplikasi Blended Learning Menggunakan Metode Vector Space Model," Ultimatics, vol. 8, no. 2, pp. 92-101, 2016.

[4] P. Dasar, V. B. Wicaksono, and S. W. Sihwi, "Analisis Perbandingan Metode Vector Space Model dan Weighted Tree Similarity dengan Cosine Similarity pada kasus Pencarian Informasi Pedoman Analisis Perbandingan Metode Vector Space Model dan Weighted Tree Similarity dengan Cosine Similarity pada kasus P,” ITSmart, vol. 4, no. 2, pp. 73-83, 2015.

[5] Putri Elfa Mas'udia, M. D. Atmadja, and L. D. Mustafa, "Information Retrieval Tugas Akhir dan Perhitungan Kemiripan," Simetris, vol. 8, no. 1, pp. 355-362, 2017.

[6] S. Y. Baskoro, A. Ridok, and M. T. Furqon, "Pencarian Pasal pada Kitab Undang-Undang Hukum Pidana (KUHP) Berdasarkan Kasus menggunakan Metode Cosine Similarity dan Latent Semantic Indexing (LSI),” J. Environ. Eng. Sustain. Technol., vol. 2, no. 2, pp. 83$88,2015$.

[7] M. Mastur, F. H. Rachman, and F. Solihin, “Efektivitas Penggunaan Stoplist Kata Umum dari Dokumen Hasil Klasifikasi Pretopology," Konvergensi, vol. 13, no. 1, pp. 1-10, 2017.

[8] D. Priyanti and S. Iriani, "Sistem Informasi Data Penduduk Pada Desa Bogoharjo Kecamatan Ngadirojo Kabupaten Pacitan," Indones. J. Netw. Secur., vol. 2, no. 4, pp. 55-61, 2013.

[9] D. Susandi and U. Sholahudin, "Pemanfaatan Vector Space Model pada Penerapan Algoritma Nazief Adriani , KNN dan Fungsi Similarity Cosine untuk Pembobotan IDF dan WIDF pada Prototipe Sistem Klasifikasi Teks Bahasa Indonesia," ProTekInfo, vol. 3, no. 1, pp. 22-29, 2016.

[10] S. Fauziah, D. N. Sulistyowati, and T. Asra, "Optimasi Algoritma Vector Space Model dengan Algoritma K-NEAREST NEIGHBOUR pada Pencarian Judul Artikel Jurnal," Pilar Nusa Mandiri, vol. 15, no. 1, pp. 21-26, 2019.

[11] A. Deteksi and K. Tugas, “Aplikasi Deteksi Kemiripan Tugas Akhir,” Matrik, vol. 16, no. 2, pp. 5-10, 2017.

[12] A. D. Muktiari, M. A. Bijaksana, and B. A. Wahyudi, "Pembangunan Ensiklopedia Kosa Kata Al Qur' an Menggunakan Generalized Vector Space Model dan Semantics Relatedness," e-Proceeding Eng., vol. 5, no. 3, pp. 7823-7831, 2018.

[13] W. Komputer, Panduan Belajar MySQL Database Server, 1st ed. Jakarta Selatan: Media Kita, 2010.

[14] S. Haryanti and T. Irianto, "Rancang Bangun Sistem Informasi E-Commerce Untuk Usaha Fashion Studi Kasus Omah Mode Kudus," J. Speed - Sentra Penelit. Eng. dan Edukasi, vol. 3, no. 1, pp. 8-14, 2011. 